\title{
Surface Reaction Films from Amine-Based Organic Friction Modifiers and Their Influence on Surface Fatigue and Friction
}

\author{
Siavash Soltanahmadi ${ }^{1}$ Erfan Abedi Esfahani ${ }^{1} \cdot$ lleana Nedelcu ${ }^{2} \cdot$ Ardian Morina $^{1} \cdot$ Marcel C. P. van Eijk ${ }^{2}$. \\ Anne Neville ${ }^{1}$
}

Received: 1 April 2019 / Accepted: 6 June 2019 / Published online: 22 June 2019

(C) The Author(s) 2019

\begin{abstract}
Surface reactive additives are crucial in the lubrication of surfaces experiencing cyclic contact. The combination of additives in the lubricant, on the material surface and the complex tribo-contact conditions hinders the design of additive packages which can simultaneously protect steel surfaces from wear and fatigue. Amine-based Organic Friction Modifiers (OFMs) influence the tribological performance of steel surfaces. This study investigates the tribochemical impact of three amine-based OFMs in combination with Zinc DialkylDithioPhosphate (ZDDP) on tribological performance, particularly surface fatigue, for steel surfaces in severe rolling-sliding contacts. The thickness of reaction films was tracked throughout experiments and the chemistry of reaction films was examined using X-ray Photoelectron Spectroscopy (XPS). Results highlight the impact of the OFM polar moiety on tribological performance and its influence on chemical composition of tribo-reaction films and their formation kinetics. The combination of selected OFMs with ZDDP reduces frictional forces and can mitigate surface fatigue under certain conditions.
\end{abstract}

\section{Graphic Abstract}
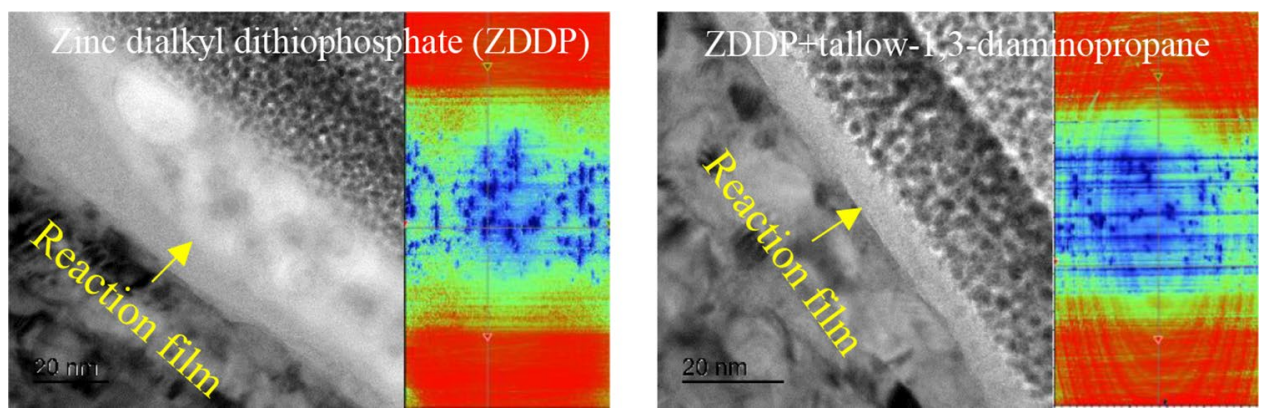

Keywords Micropitting $\cdot$ Amine OFMs $\cdot$ ZDDP $\cdot$ XPS

\section{Introduction}

Premature failures and surface fatigue of bearings in wind turbine gearboxes significantly decrease their lifespan.

Siavash Soltanahmadi

s.soltanahmadi@leeds.ac.uk

1 IFS, School of Mechanical Engineering, University of Leeds, Leeds LS2 9JT, UK

2 SKF Research \& Technology Development, 3430 DT Nieuwegein, The Netherlands Lubricant additives contribute to factors leading to micropitting, i.e., a prevalent surface fatigue in wind turbine gearboxes. ZDDP is an essential additive to mitigate excessive wear and scuffing, however, it has also been shown to accelerate micropitting [1]. In our previous paper [2], we showed that an amine-based OFM in combination with ZDDP can 
alleviate micropitting on steel surfaces under defined conditions. The effect of different OFMs on surface fatigue, however, cannot be generalised to be detrimental or beneficial owing to the broad OFM category encompassing molecules with different polar head chemistry. This can be evidenced from results showing an oleic acid OFM was not effective to inhibit micropitting in harsh tribo-contacts, while signs of improvement were observed in less severe contacts [3]. Therefore, the chemical composition of OFMs has an impact on surface fatigue performance, and more systematic studies are required to reveal the impact of different chemistries of amine-based OFMs on micropitting performance of wind turbine gearbox lubricants. Moreover, the study of oleic acid [3] was conducted in the absence of other lubricant additives, nevertheless chemical interactions between additives in the lubricant and their competition in terms of surface chemisorption [4] are indications of the importance of studying OFMs in combination with other lubricant additives. Accordingly, this study elucidates the tribochemical influence of amine-based OFMs in combination with ZDDP anti-wear additive.

The chemistry of tribo-induced films from amine-based OFMs in combination with ZDDP is not fully understood nor is their impact on surface fatigue. This study investigates the influence of three different amine-based OFMs on friction, surface fatigue and composition of surface reactions films. The OFMs differ in the polar moiety. In this study, we show that OFM's chemistry has an influence on the surface reaction film thickness and composition and hence alters tribological performance. Results in this study also highlight the influence of tribological parameters such as surface roughness and contact geometry on reaction film formation. Among three OFM chemistries, Ethoxylated (2) Tallowalkyl-Amine (ETA) showed the lowest friction, thinnest reaction film and larger mild wear and N-Tallow-1,3-DiaminoPropane (TDP) showed the highest film build-up kinetics and superior surface fatigue performance showing the impact of polar head chemistry of OFMs on tribological performance.

\section{Methodology}

\subsection{Materials and Tribotesting}

A PCS Instruments Mini Traction Machine (MTM) was used in this work to investigate the frictional characteristics of amine-based OFMs and a Spacer Layer Image Mapping (SLIM) apparatus attached to the MTM was used to inspect the kinetics of the reaction film formation. The MTM-SILM tribometer is explained in authors' previous paper [2]. The materials and test parameters are shown in Table 1. Experiments were conducted with two roughness values while the balls used for both sets were the same. Lubricant temperature, slide-to-roll ratio, entrainment speed for all Constant Entrainment-Speed (CES) steps and entrainment speed range for Stribeck curve were fixed for both sets of experiments. In tests with the rough disc specimen two Stribeck measurements were performed in comparison to eight Stribeck curves on the smooth disc. The rough and the smooth discs are abbreviated to SR and SS. Briefly, once the oil in the reservoir reached a steady temperature of $90{ }^{\circ} \mathrm{C}$, a Stribeck curve $(3000-15 \mathrm{~mm} / \mathrm{s})$ was measured which was then followed by a CES step at a constant entrainment speed of $100 \mathrm{~mm} / \mathrm{s}$ for a pre-defined time interval. The SLIM coupled with the MTM used to measure the thickness of the reaction film formed on the ball surface after every CES step.

Table 1 Experimental set up for friction tests

\begin{tabular}{|c|c|c|}
\hline Specimens & Ball & Disc \\
\hline Material and diameter & AISI 52100 steel—19.05 mm & $\begin{array}{l}\text { AISI } 52100 \\
\text { steel- } \\
46 \mathrm{~mm}\end{array}$ \\
\hline Roughness $\left(\mathrm{R}_{\mathrm{a}}\right.$ in $\left.\mathrm{nm}\right)$ & 16 & $\begin{array}{l}\text { SR: } 90-110 \\
\text { SS: } 8\end{array}$ \\
\hline $\mathrm{P}_{\max }(\mathrm{GPa})$ & 1 & \\
\hline Temperature & $90^{\circ} \mathrm{C}$ & \\
\hline CES-step duration between film mapping (in minutes) & $5,10,15,30,60,60,60$ & \\
\hline $\begin{array}{l}\text { Stribeck diagram measurement after a total CES contact time of } \\
\text { (in minutes) }\end{array}$ & $\begin{array}{l}\text { SR: } 0 \text { (initial), } 240 \\
\text { SS: } 0 \text { (initial), 5, 15, 30, 60, 120, 180, } 240\end{array}$ & \\
\hline Mapping after a total CES contact time of (in minutes) & 0 (initial), 5, 15, 30, 60, 120, 180, 240 & \\
\hline Slide-to-roll ratio throughout the test & $5 \%$ & \\
\hline Entrainment speed in all CES steps & $100 \mathrm{~mm} / \mathrm{s}$ & \\
\hline Entrainment speed range for Stribeck curve & $3000-15 \mathrm{~mm} / \mathrm{s}$ & \\
\hline
\end{tabular}


The impact of OFMs on surface fatigue was evaluated after a million contact cycles using a modified MicroPitting Rig (MPR) from PCS instruments. Micropits appear on the surface of a spherical roller, $12 \mathrm{~mm}$ in diameter, which sits between three larger and equal-diameter counterbodies. Rollers were circumferentially polished to a roughness value of $\mathrm{R}_{\mathrm{q}}=50 \pm 5 \mathrm{~nm}$. The counterbodies were cylindrical rings and ground-finished transverse to the rotation-direction with a roughness value of $R_{q}=500 \pm 50 \mathrm{~nm}$ in order to accelerate surface fatigue. Surface fatigue test parameters are indicated in Table 2 and more details including schematic of the rig can be obtained in our previous paper [2].

\subsection{Lubricants and OFMs}

The Base Oil (BO) used was a low-viscosity Poly Alpha Olefin (PAO) base stock. The kinematic viscosity of the base oil was $4.0 \mathrm{cSt}$ at $100{ }^{\circ} \mathrm{C}$. ZDDP, the anti-wear additive, was blended in PAO to a phosphorus concentration of $0.08 \mathrm{wt} \%$. OFMs were provided by AkzoNobel and were commercial products used in different industry sectors. Chemistry of OFMs is illustrated in Table 3. Amine-based OFMs are amphiphilic molecules. The hydrophobic part is not a chemically-functional group and influences physical parameters such as steric hindrance, solubility and critical

Table 2 Test parameters in the surface fatigue study

\begin{tabular}{lc}
\hline Specimens & Roller: 52100 \\
& steel, Rq: \\
$50 \mathrm{~nm} \mathrm{Hv}:$ \\
785 \\
& Rings: 52100 \\
& steel, Rq: \\
& $500 \mathrm{~nm}$, \\
& $\mathrm{Hv}: 745$ \\
Maximum hertzian pressure $\left(P_{\max }\right)$ & $1.5 \mathrm{GPa}$ \\
Temperature & $90{ }^{\circ} \mathrm{C}$ \\
Entrainment speed & $1 \mathrm{~m} / \mathrm{s}$ \\
Slide-to-roll ratio & $2 \%$ \\
\hline
\end{tabular}

micelle concentration. Although the hydrophobic part fulfils friction reduction, the efficiency of the friction reduction is significantly influenced by the polar moiety. This results from the affinity of the hydrophilic parts to surfaces and their interactions with the other lubricant additives.

Three OFMs were investigated in this work, a primary amine (i.e. Tallowalkyl-Amine (TA)), a diamine (i.e. TDP) and a gently ethoxylated primary amine (i.e. ETA) which has two terminating hydroxyl groups. The amine-based OFM molecules comprised the same alkyl chain, i.e. tallow alkyl group, to eliminate the influence of hydrophobic part and investigate the effect of the functional group. The defined OFMs were blended in the oil using an ultrasound bath at $45-50{ }^{\circ} \mathrm{C}$ for $30 \mathrm{~min}$. Surface fatigue investigations and friction measurements in the SS configuration were carried out with the addition of OFMs at a concentration of $1 \mathrm{wt} \%$, while MTM experiments in the SR configuration were performed with $0.5 \mathrm{wt} \%$ of OFMs. A higher concentration of $1 \mathrm{wt} \%$ was selected due to its superior surface fatigue performance [2] under conditions defined in this study.

\subsection{Surface Characterisation}

\subsubsection{Surface Imaging}

Rolling tracks resulting from surface fatigue tests were analysed utilising a Bruker's NPFLEX which uses White Light Interferometry (WLI) to capture surface images. An imageprocessing feature, i.e. multiple region analysis, incorporated in Vision64 software was used to quantify surface fatigue damageto understand and compare the OFM performance. This technique is explained in our previous paper [7]. A Carl Zeiss Supra 55 Field Emission Gun (FEG) and a Carl Zeiss EVO MA15 Scanning Electron Microscope (SEM) were used to examine wear scars/rolling tracks and surface reaction films in wear scars/rolling tracks.

A FEI Tecnai TF20 FEG-Transmission Electron Microscope (TEM) was employed to obtain images from crosssectional lamellas which were prepared through Focused Ion Beam (FIB) milling using a FEI Nova 200 NanoLab

Table 3 Molecular chemistry of amine-based OFMs investigated in this study

Tallowalkyl-Amine (TA)

$\mathrm{R}$ chain was a tallow alkyl group (C:12-18) which has a cis to trans ratio of 8-20 [5] indicating the presence of several kinks in the alkyl chain group depending on the relative position of cis bonds in the alkyl chain. The exact composition of tallow hydrocarbon chain is not known in this study, however; a typical composition, chain length distribution and degree of unsaturation in tallow can be found in a paper by Boyer et al. [6] 
SEM. The TEM lamellas were collected from the surfaces lubricated with $\mathrm{BO}+\mathrm{ZDDP}$ and $\mathrm{BO}+\mathrm{ZDDP}+\mathrm{TDP}$ after a million load cycles. From each roller, an area close to the edge of a micropit was designated for FIB milling and a lamella was cut perpendicular to the rolling-sliding direction and thinned using a $\mathrm{Ga}$ ion beam. Three layers of $\mathrm{Pt}$ were deposited on the surface to protect the surface from high-energy $\mathrm{Ga}$ ion beam incidences. The nearest layer to the surface was a $20 \mathrm{~nm}$ Pt layer which was plasma sputtered (with no Ga source) to the surface of the whole sample prior to introducing the sample to the SEM chamber for FIB milling. This layer was deposited to supress damage which occur later during Ga-assisted Pt-strip deposition inside the SEM chamber.

\subsubsection{Surface Chemical Analysis}

XPS analyses were performed using a PHI 5000 Versa Probe $^{\mathrm{TM}}$ spectrometer (Ulvac-PHI Inc, Chanhassen, MN, USA) which uses a monochromatic Al K $\alpha \mathrm{X}$-ray source $(1486.6 \mathrm{eV})$. Prior to the XPS analysis, residual oil on the surface was removed by flushing with $\mathrm{n}$-heptane followed by a 3-min ultrasonic cleaning also in n-heptane. Survey spectra with an energy step size of $1 \mathrm{eV}$ were obtained from different locations in order to accurately identify the wear scar. Detailed High Resolution (HR) spectra were acquired from small areas inside the wear scar with a beam size of $100 \mu \mathrm{m}$ and a power of $23.7 \mathrm{~W}$ in a fixed analysed transmission mode. The energy step size of $0.05 \mathrm{eV}$ was determined for the $\mathrm{O}, \mathrm{Fe}, \mathrm{P}$, and $\mathrm{S}$ acquisition. The energy step size was set to 0.1 for $\mathrm{C}$ and $\mathrm{Zn}$ spectra. During spectra acquisition the residual chamber pressure was maintained lower than $5 \times 10^{-7} \mathrm{~Pa}$.

The detailed XPS spectra were fitted using CASAXPS software (version 2.3.16, Casa Software Ltd, UK) with Gaussian-Lorentzian functions after subtracting a Shirley background. Aliphatic carbon Binding Energy (BE) was referred to $285.0 \mathrm{eV}$ to compensate the surface charging effect. In accordance to spin-orbit splitting, a 2:1 arearatio-constraint was considered for the two components of the $2 p$ peaks $\left(p_{3 / 2}\right.$ and $\left.p_{1 / 2}\right)$ to perform $P(P 2 p)$ and $S(S$ $2 p)$ signal fittings $[8,9]$. In addition, position-differenceconstraints of $0.85 \mathrm{eV}$ and $1.25 \mathrm{eV}$ were used to confine two components of the $\mathrm{P}$ and $\mathrm{S}$ signals, respectively [8]. $\mathrm{Zn}$ Auger $\left(\mathrm{L}_{3} \mathrm{M}_{4,5} \mathrm{M}_{4,5}\right)$ signals were obtained and fitted using two peaks to extract two signals $\left({ }^{1} \mathrm{G}\right.$ and $\left.{ }^{3} \mathrm{~F}\right)$ [10]. A modified Auger parameter $\left(\alpha^{\prime}\right)$ was calculated by adding together $\mathrm{Zn} 2 \mathrm{p}_{3 / 2}$ BE and $\mathrm{Zn} \mathrm{L}_{3} \mathrm{M}_{4,5} \mathrm{M}_{4,5}{ }^{1} \mathrm{G}$ Kinetic Energy (KE) values. $\alpha$ ' physically represents the chemical state of $\mathrm{Zn}$ in the reaction films from additives which will be discussed more in detail in the results and discussion sections.

\section{Results}

\subsection{Reaction Film Build-Up}

It is important to study the evolution kinetics of the triboreaction film which coincides with running-in processes influencing wear and surface fatigue performances. Figure 1 compares the influence of amine-based OFMs on the growth kinetics and thickness of overall triboreaction films over $4 \mathrm{~h}$ of tribo-contacts. It is evident that the addition of OFMs reduces the growth rate of the triboreaction film, indicating that OFMs delay the ZDDP-derived surfacefilm formation. The delaying impact of amine-based friction modifiers on anti-wear reaction film formation has been reported in previous studies $[11,12]$. The delaying impact of OFMs increases along the series of additives ETA > TA > TDP. BO + ZDDP generated a 65-nm-thick film at the initial Stribeck curve measurement, followed by a further 80-nanometer film which was formed subsequent to a 5-min CES step resulting in an ultimate 145-nm-thick film. At the same time TDP + ZDDP induced a few nanometer-thick film, while there was no SLIM-sensitive film on the surface of ETA + ZDDP and a film started to emerge from TA + ZDDP.

The SLIM is able to quantify the tribofilm thickness up to a maximum value of $200 \mathrm{~nm}$ and, therefore, when the ZDDP-film thickness reached a value of greater than $200 \mathrm{~nm}$ after an hour of tribo-contacts, further data could not be obtained from SLIM images. However, SLIM images can reveal extra information implying a steadystate tribofilm after $2 \mathrm{~h}$ of testing in BO +ZDDP. Tribofilm thicknesses in OFM-containing lubricants levelled out after $3 \mathrm{~h}$ of contact and therefore, OFMs delayed both the tribofilm formation and the time required to achieve a steady-state by decaying the kinetics of surface-film formation. Among the examined OFMs, it appeared that the overall reaction film thickness is reversely proportional to the delaying extent. ETA induced the thinnest tribofilm (around $100 \mathrm{~nm}$ ) on the surface while lubricants containing TA and TDP formed tribofilms with a similar thickness.

\subsection{Impact of OFM's Molecular Structure on Friction}

Stribeck friction results at the start of the test (black curve) and after four hours of CES tribo-contacts (red curve) can be observed in Fig. 2a. At the start of the test, at which the triboreaction film has not yet formed, the initial Stribeck curve of the BO+ZDDP was similar to that of the base oil (not shown) showing a gradual increase of friction with a decrease in the lubricant entrainment speed. Considering 
Fig. 1 Triboreaction film evolution in different lubricant formulations over $4 \mathrm{~h}$ of tribocontact conducted in the SR configuration. The top section presents SLIM images and circular contact zones in the interference images are $280 \mu \mathrm{m}$ in diameter. The bottom graph shows the triboreaction film growth and thickness over CES step intervals. Error bars in the plot represent the minimum and maximum film thicknesses detected on the surfaces

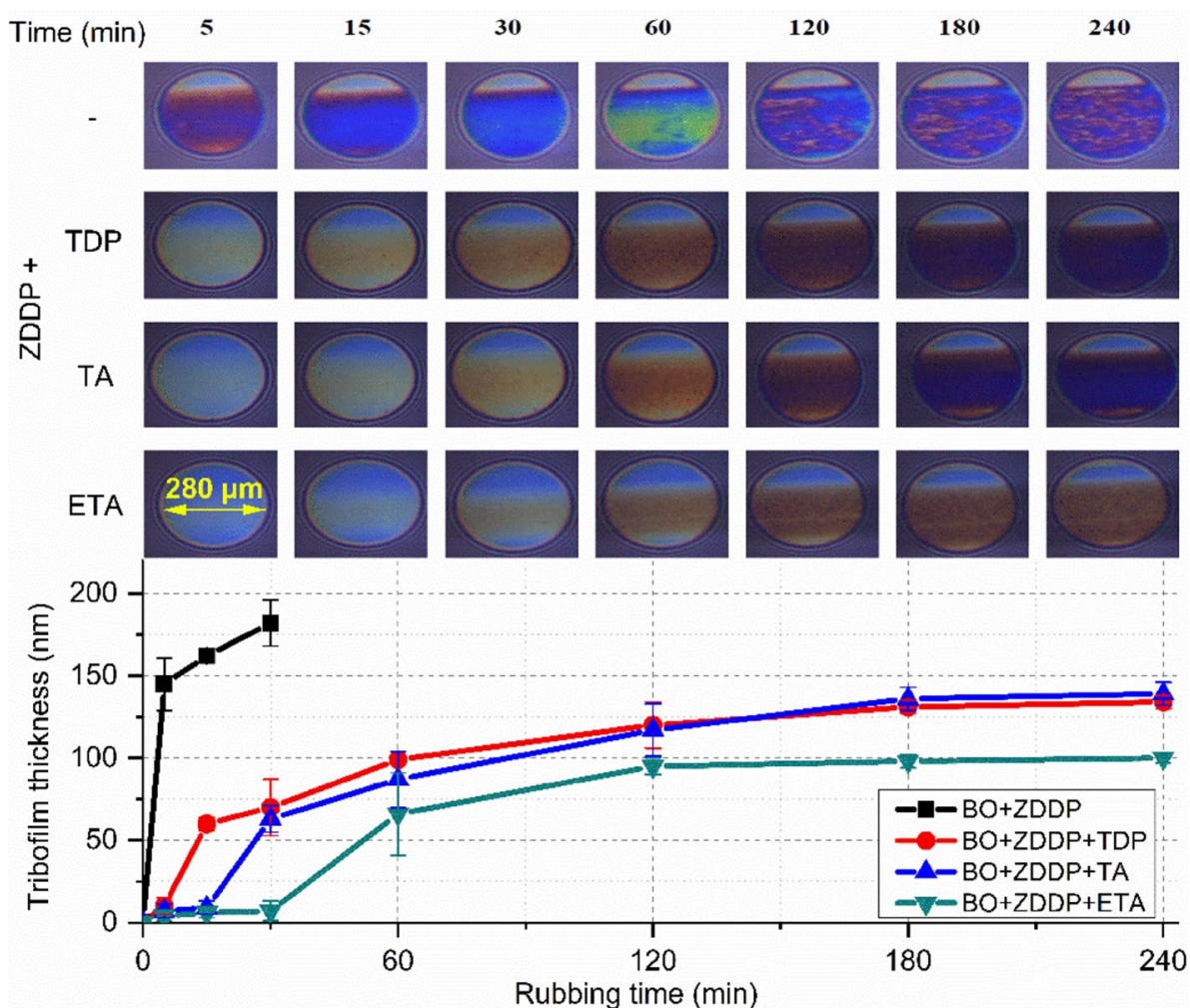

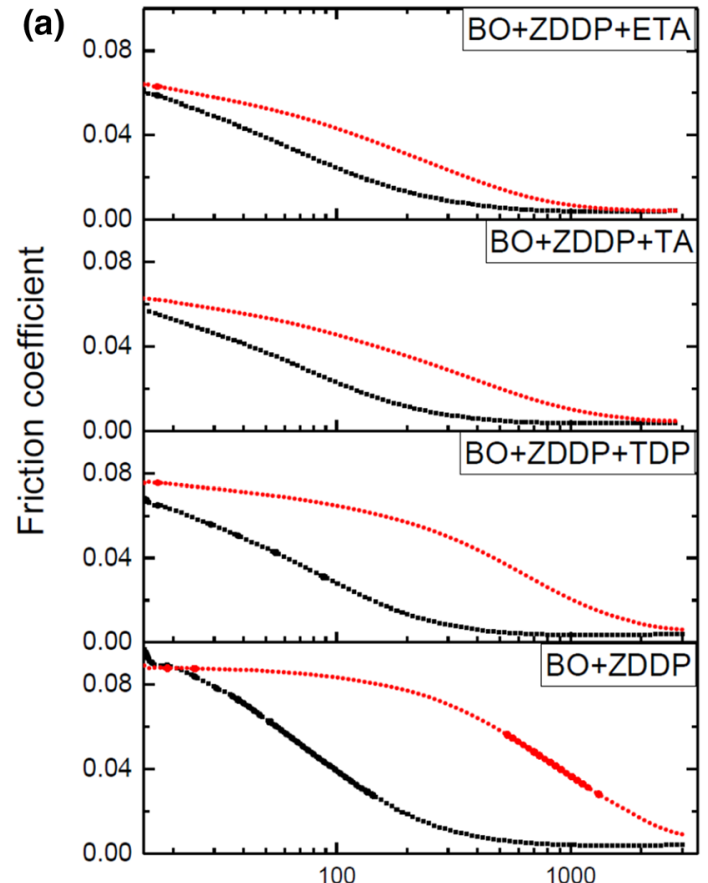

Entrainment speed $(\mathrm{mm} / \mathrm{s})$
Fig. 2 The influence of OFMs on a Stribeck friction curves and $\mathbf{b}$ constant speed 4-h contacts. In section (a), the initial Stribeck curve is plotted in black and the Stribeck measurement after $4 \mathrm{~h}$ of con-

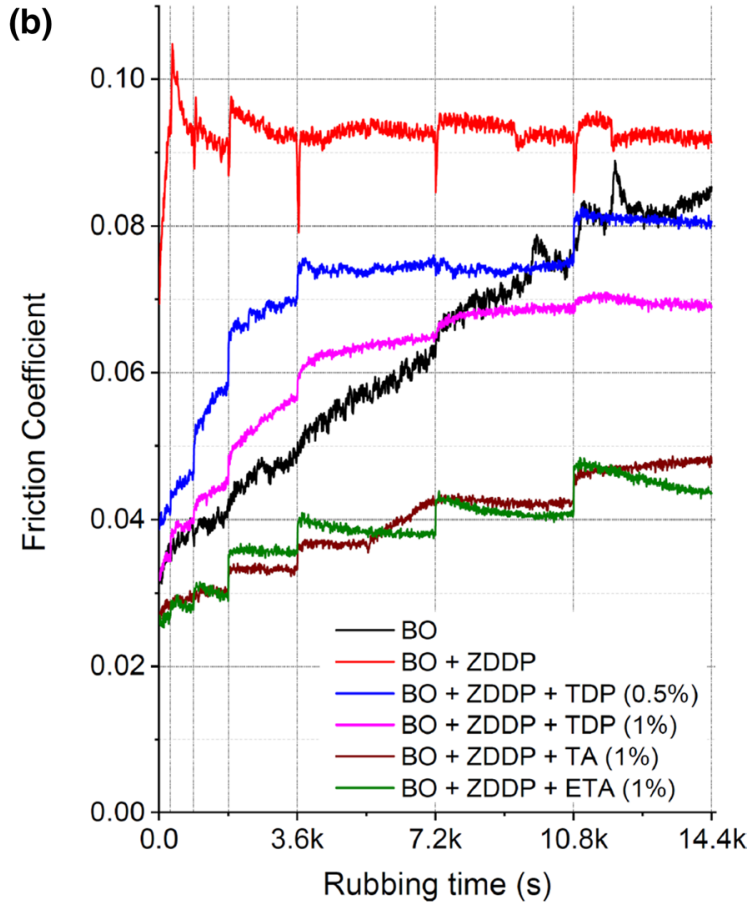

tacts is plotted in red. Vertical lines in section (b) indicate the time at which Stribeck curves were measured 
the initial Stribeck friction at the start of the test showing a relativity low friction coefficient of around 0.04 at $100 \mathrm{~mm} / \mathrm{s}$, severe solid-solid contacts and hence a high friction value was not expected within the intermediate speed range $(100-1000 \mathrm{~mm} / \mathrm{s})$. However, the build-up of ZDDP tribofilm at the interface induced a significant rise in following Stribeck friction measurements, especially within the intermediate speed range $(100-1000 \mathrm{~mm} / \mathrm{s})$. The impact of ZDDP on escalating friction within the intermediate entrainment speed range has been discussed elsewhere [2].

Addition of OFMs to the lubricant decreased the boundary coefficient of friction (entrainment speed $<100 \mathrm{~mm} / \mathrm{s}$ ) at the start of tests which can be attributed to the adsorbed OFM films on steel surfaces prior to ZDDP-film formation. After 4 hours of testing, OFMs reduced the friction coefficient within the speed range of less than $1000 \mathrm{~mm} / \mathrm{s}$ which indicates that OFMs decayed the friction-enhancing behaviour of the ZDDP film. In Fig. 2b, which shows friction coefficient results during the CES steps at a constant speed of $100 \mathrm{~mm} / \mathrm{s}$, the friction behaviour of BO is also included for reference.

In contrast to $\mathrm{BO}$ which exhibited a persistent increase in friction, the friction coefficient of lubricants with ZDDP/ OFMs remained almost constant during each CES step (fixed-speed) which is indicative of a steady-state reaction film on the surface. The friction coefficient of OFM-containing lubricants showed an increase following every Stribeck step. The increase in the friction coefficient can result from wear which roughens the smooth surfaces and/or growth of ZDDP-tribofilm on the smooth surfaces which has been shown to escalate the friction coefficient of steel surfaces [2]. The friction behaviour was found to depend on the OFM chemistry and compared to $\mathrm{BO}+\mathrm{ZDDP}$, a friction reduction of $25 \%, 48 \%$ and $52 \%$ was achieved by addition of TDP, TA and ETA to the lubricant, respectively.

Wear scars from different additive chemistries appeared similar under SEM with a slight decrease in wear scar width as a result of OFMs in the lubricant. As shown in Fig. 3, more scratches on the steel surface and a thinner and topographically more homogenous reaction film were observed when TDP was present in the lubricant formulation.

\subsection{Surface Reaction Film Chemistry}

Wear scars on MTM balls in the SR configuration were analysed by XPS. The fitted HR spectra of the tribofilm elements in wear scars from $\mathrm{BO}+\mathrm{ZDDP}$ and $\mathrm{BO}+\mathrm{ZDDP}+\mathrm{TDP}$ are presented in Fig. 4 for comparison. The other spectra were fitted with the same procedure presented in Fig. 4 and detailed results from fitted spectra are shown in Table 4. In addition, chemical bonds corresponding to a peak appeared at a specific binding energy are detailed in the table. The $\mathrm{C} 1 \mathrm{~s}$ spectra are resolved to four signals. The signal at around $288.8-289.0 \pm 0.1 \mathrm{eV}$ was slightly diminished in the spectra from TDP. The signal can be assigned to $\mathrm{C}=\mathrm{O}$ bond (carbonate and/or carboxylic) which can be an indication of oil oxidation. The peak at around $286.3 \pm 0.1 \mathrm{eV}$ in the spectra from ETA was enhanced which can be an indication of adsorbed ETA on the surface. The enhanced intensity of the peak at $286.3 \pm 0.1 \mathrm{eV}$, however, cannot be assigned explicitly to the adsorbed ETA, as it might originate from $\mathrm{P}-\mathrm{O}-\mathrm{C}$ bond in phosphate chains. On the other hand, concentration of $\mathrm{P}$ in the film from ETA was decreased compared to that from BO + ZDDP which implies contribution of hydroxyl from ETA to this peak.

The $\mathrm{O} 1 \mathrm{~s}$ signal consisted of two peaks in all tribofilms with the most intense peaks at $531.4-5 \pm 0.1 \mathrm{eV}$ assigned to Non-Bridging Oxygen (NBO) from phosphate chains $(-\mathrm{P}=\mathrm{O}$ and $\mathrm{P}-\mathrm{O}-\mathrm{Zn})$, carbonates and hydroxides in all tribofilms and nitrates in tribofilms from OFMs [13]. The peak at $533.0 \pm 0.1 \mathrm{eV}(\mathrm{BO}+\mathrm{ZDDP})$ and $532.6-532.8 \pm 0.1 \mathrm{eV}$ $(\mathrm{BO}+\mathrm{ZDDP}+\mathrm{OFMs})$ corresponds to Bridging Oxygen (BO) from phosphate chains ( $\mathrm{P}-\mathrm{O}-\mathrm{P} / \mathrm{P}-\mathrm{O}-\mathrm{C})$. The $\mathrm{P} 2 \mathrm{p}$ signal originated from $\mathrm{P}$ in phosphate chains in all tribofilms. The BE difference between $\mathrm{Zn} 3 \mathrm{~s}$ and $\mathrm{P} 2 \mathrm{p}_{3 / 2}$ can provide an indication regarding the phosphate chain length showing a higher value for a shorter chain length [10]. With almost the
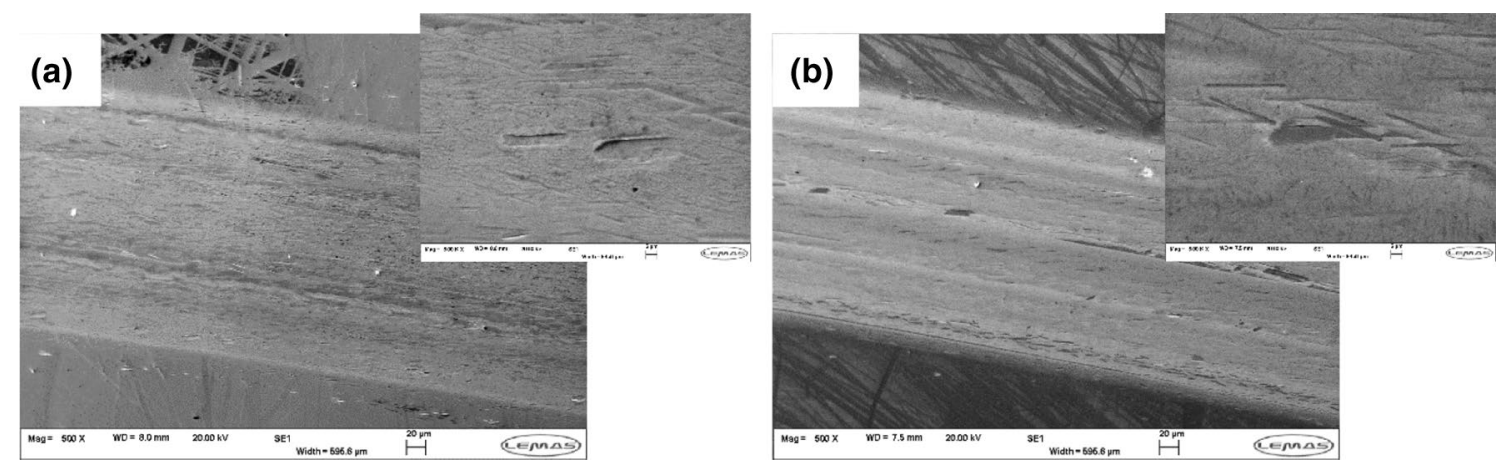

Fig. 3 Wear scar SEM-images from a BO + ZDDP and b BO + ZDDP + TDP lubricants 
Fig. 4 Detailed XPS spectra showing a $\mathrm{P} 2 \mathrm{p}$ and $\mathrm{Zn} 3 \mathrm{~s}$, b S $2 \mathrm{p}, \mathbf{c ~ Z n ~ L}{ }_{3} \mathrm{M}_{4,5} \mathrm{M}_{4,5}$ and $\mathbf{d} \mathrm{N} 1 \mathrm{~s}$ signals. In $\mathbf{a}-\mathbf{c}$, the spectra were collected from BO + ZDDP (top-plotted in red) and $\mathrm{BO}+\mathrm{ZDDP}+\mathrm{TDP}$ (bottomplotted in green) lubricant formulations
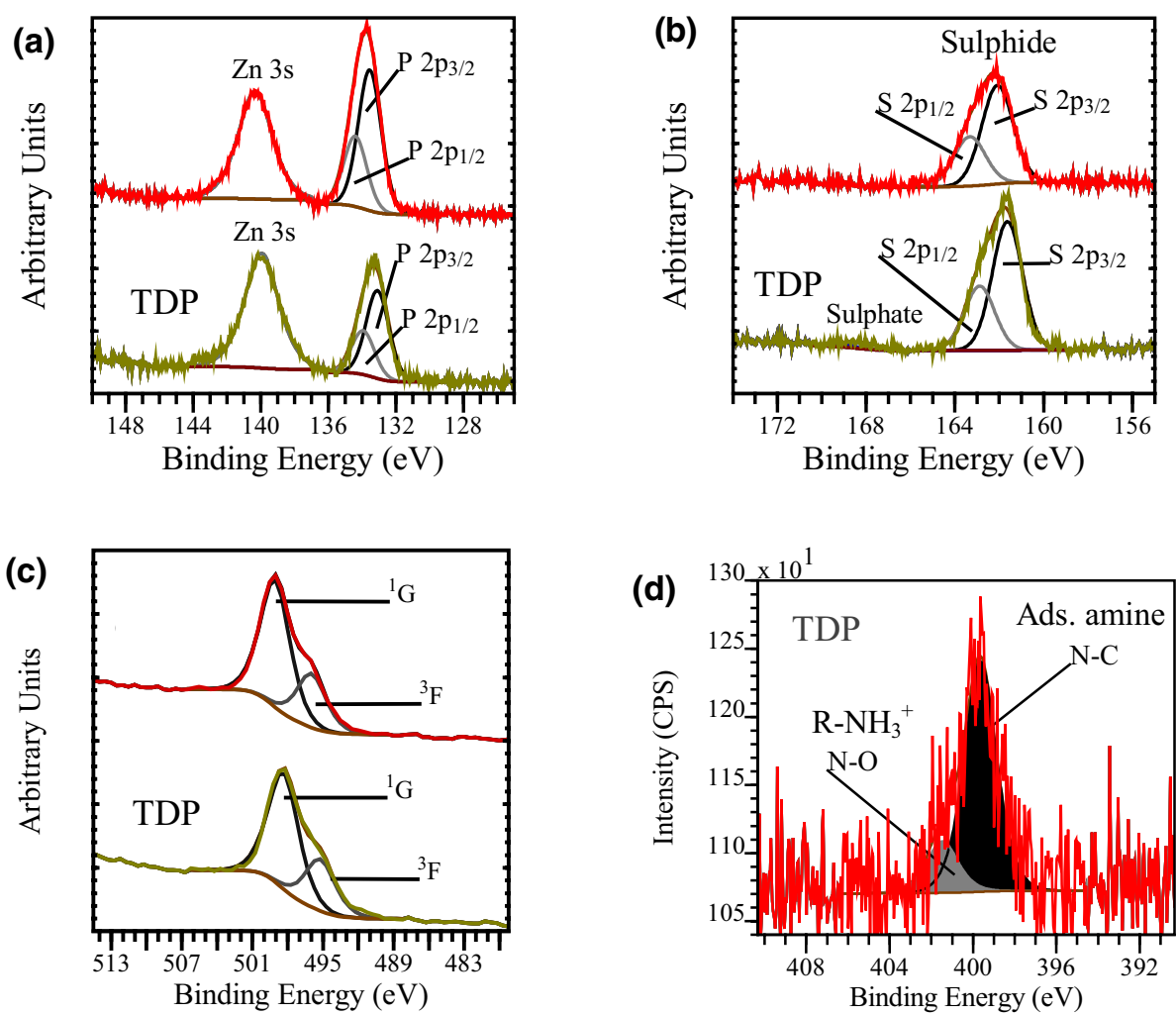

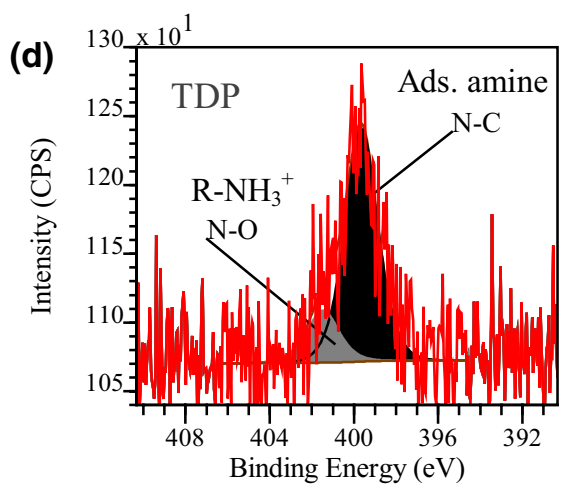

same value of $\mathrm{Zn} 3 \mathrm{~s}-\mathrm{P} 2 \mathrm{p}_{3 / 2} \mathrm{BE}$ in all tribofilms, a similar phosphate chain length is expected for all tribofilms.

Due to the lack of specific reference spectra from nitrogen-based compounds and low signal to noise ratio, $\mathrm{N}$ $1 \mathrm{~s}$ peak was difficult to interpret. As shown in Fig. 4 and Table 4, a peak appeared at $399.7-8 \pm 0.1 \mathrm{eV}$ that can be attributed to $\mathrm{N}-\mathrm{C} / \mathrm{N}-\mathrm{H}$ bonds in adsorbed OFMs [14], R-(HN)-P bond [15] and N in Amine Phosphate (AP) [16]. Therefore, this peak can be assigned to adsorbed OFM molecules to the surface or residual compound(s) from ZDDP and $\mathrm{OFM}(\mathrm{s})$ interaction(s). The second peak in the spectra from tribofilms at $401.5-402.0 \pm 0.1 \mathrm{eV}$ can be assigned to ammonium, ammonium phosphate [15], $\mathrm{N}-\mathrm{O}$ bonds in nitrates [13] and/or ionized organic (di)amine [16]. The BE values above $400 \mathrm{eV}$ have been assigned to positively charged and protonated N-bonding state $[17,18]$, while bonding states with higher electron density appear at lower-binding energies in XPS [14]. A contribution of ammonium phosphates $[19,20]$ or/and APs [21] to the phosphate chain in tribofilms induced by lubricants containing ZDDP and dispersants has been reported using XANES and XPS [22]. The AP is formed through reaction of the pyrolytically dissociated amine group from a dispersant and decomposed ZDDP [21]. In addition, formation of AP can be inferred from energy shifts in $\mathrm{P} 2 \mathrm{p}_{3 / 2}$ peaks to values close to $133.2 \mathrm{eV}$ [16].

The first peak in S 2p spectra which varied between 161.6 and $162.1 \pm 0.1 \mathrm{eV}$ represents $\mathrm{S}$ in oxidation state of -2 (SII) and has been assigned to sulphides [23] as organic and metal sulphide. Higher ratios of $\mathrm{Zn} / \mathrm{P}$ and $\mathrm{S} / \mathrm{P}$ and greater $\alpha$ ' values for tribofilms from OFMs can be observed in Table 4 . An increase in $\alpha^{\prime}$ in Wagner plot suggests that zinc sulphide formation was partly enhanced $[23,24]$ which agrees with the greater $\mathrm{Zn} / \mathrm{P}$ and $\mathrm{S} / \mathrm{P}$ ratios. This indicates that $\mathrm{OFMs}$ can alter the state of $\mathrm{Zn}$ in the tribofilm to a certain extent. This partially originates from chemical interactions between amine and ZDDP molecules in the lubricant which influence chemical reactions leading to tribofilm formation [11]. Traces of sulphates at around 168.0-168.5 $\pm 0.1 \mathrm{eV}$ were observed in tribofilms from TDP and ETA. The $\mathrm{S}_{(\mathrm{II})} / \mathrm{P}$ ratio increased along the series of additives ETA (1.25) > TDP (1) > TA (0.75) which was coincident with the increase in concentration of sulphate in tribofilms (Table 4) implying atmospheric oxidation of the enhanced sulphides.

$\mathrm{ZnS}+\frac{3}{2} \mathrm{O}_{2} \rightarrow \mathrm{ZnO}+\mathrm{SO}_{2} \stackrel{\mathrm{O}_{2}}{\rightarrow} \mathrm{ZnO}+\mathrm{SO}_{4}$

\subsection{Influence of Additive Chemistry on Surface Fatigue Performance}

To inspect rolling tracks from different lubricant formulations, WLI images were obtained from roller surfaces and micropitted surface area (MSA) values were quantified using multiple region analysis and are indicated in Fig. 5. The cross-sectional area of rolling tracks along a line transverse to the rolling direction was obtained and 


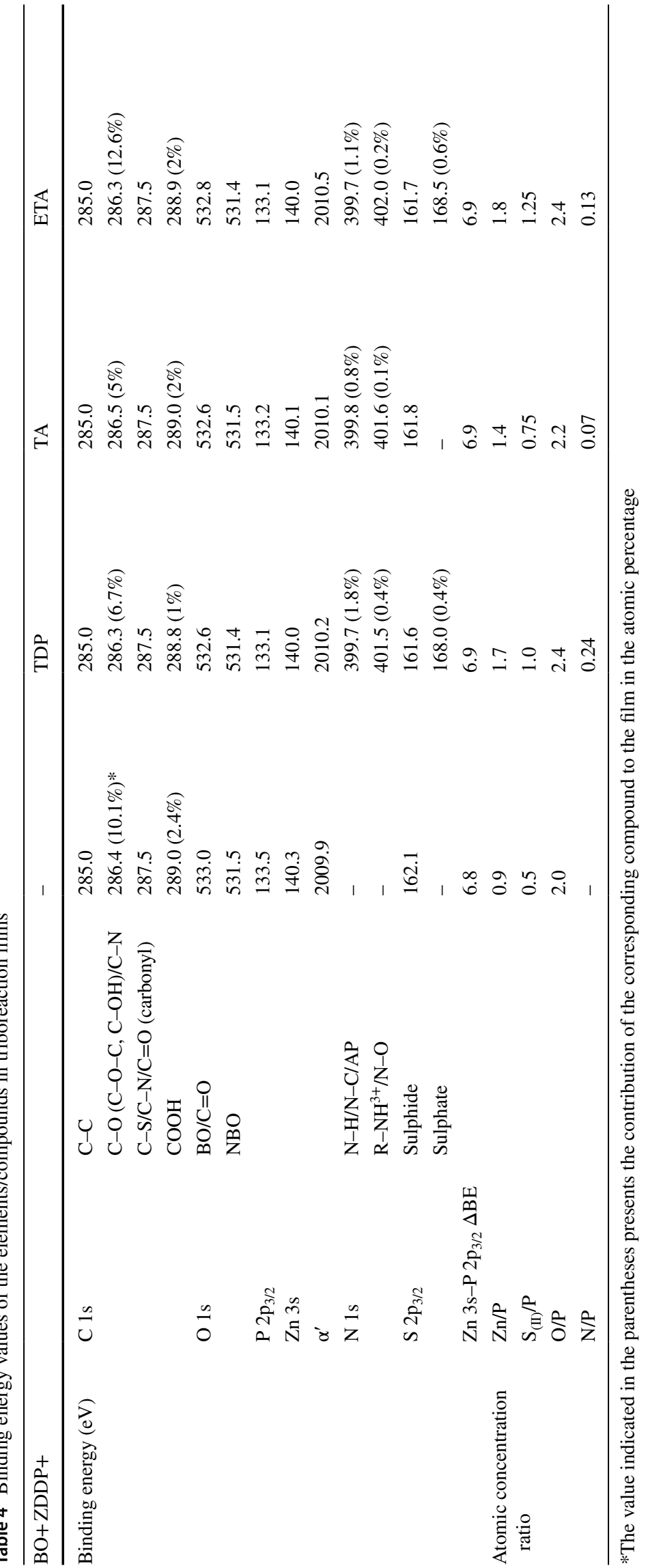



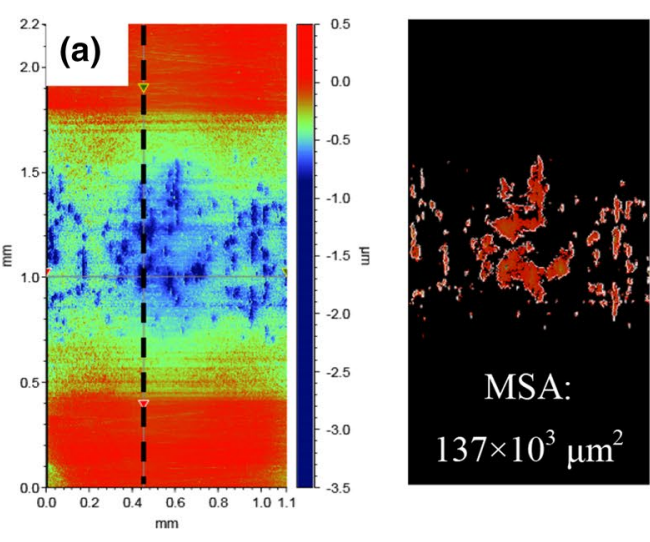

Rolling track cross-sectional area: $680 \mu \mathrm{m}^{2}$

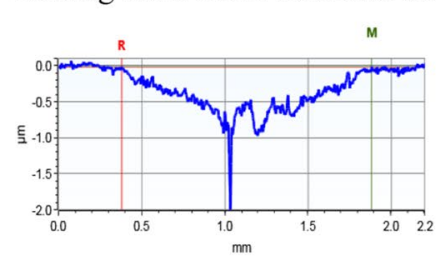

Average MSA:

$214 \times 10^{3} \pm 35$ $\mu \mathrm{m}^{2}$
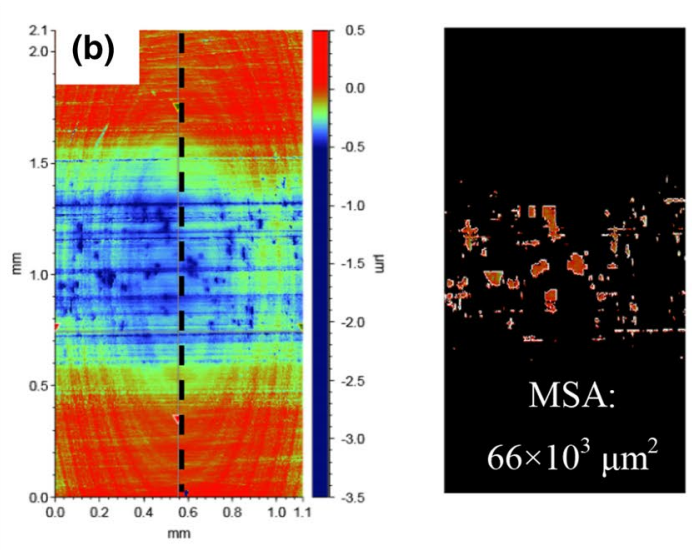

Rolling Track Cross-sectional Area: $341 \mu \mathrm{m}^{2}$

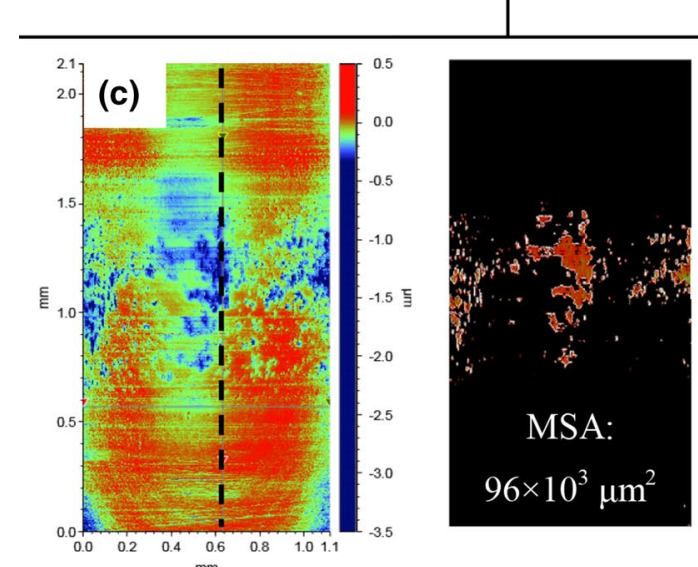

Rolling track cross-sectional area: $150 \mu \mathrm{m}^{2}$

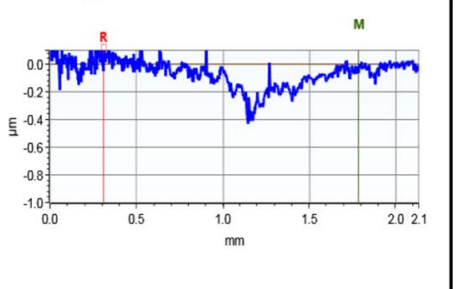

Average MSA:

$129 \times 10^{3} \pm 37$

$\mu \mathrm{m}^{2}$
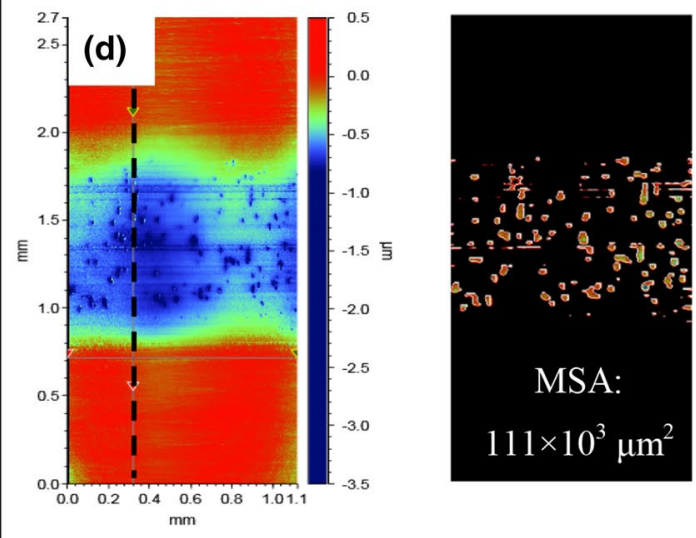

Average MSA:

$109 \times 10^{3} \pm 44$

$\mu \mathrm{m}^{2}$

Rolling track cross-sectional area: $735 \mu \mathrm{m}^{2}$

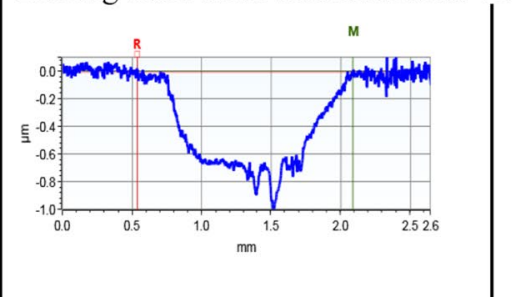

Average MSA:

$141 \times 10^{3} \pm 32$

$\mu \mathrm{m}^{2}$

Fig. 5 WLI images and corresponding MSA values and cross-sectional wear profiles obtained from MPR roller surfaces. Impacts of TDP, TA and ETA OFMs on the surface fatigue performance of the reference lubricant (BO+ZDDP) are shown in b-d sections respectively

is presented in the figure. Figure 5 also includes average MSA which was acquired from three repeats with each lubricant formulation. Average MSA values exhibited the capability of the amine-based OFMs to mitigate micropitting surface fatigue and showed an additive's chemistrydependent surface fatigue performance of OFMs. The cross-sectional rolling track profiles of TDP and TA in Fig. 5 suggested shallow rolling tracks with superficial and insubstantial micropits, while considerably deep and substantial micropits can be seen on the surface from $\mathrm{BO}+\mathrm{ZDDP}$. 
Fig. 6 SEM-images from rollers lubricated with a $\mathrm{BO}+\mathrm{ZDDP}$ and $\mathbf{b} \mathrm{BO}+\mathrm{ZDDP}+\mathrm{TDP}$ lubricants
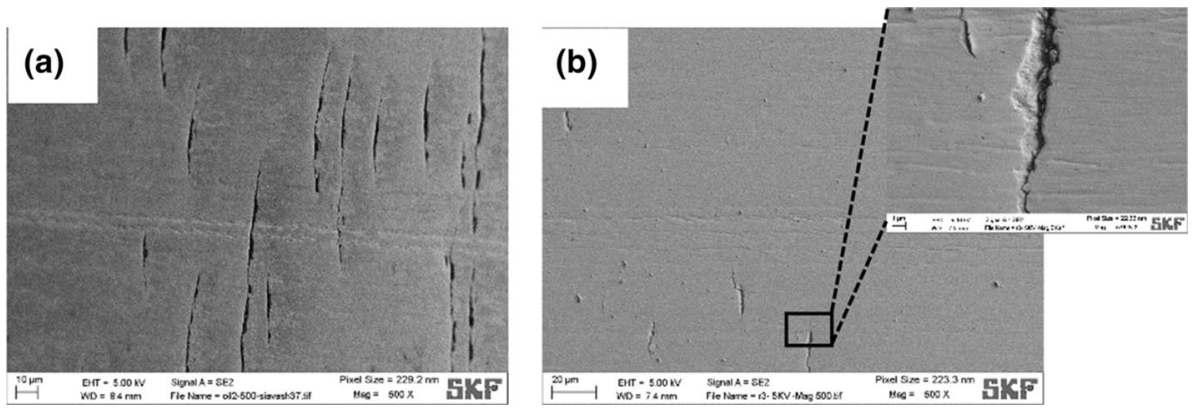

Fig. 7 Reaction films on the MPR roller surfaces from $\mathbf{a} \mathrm{BO}+\mathrm{ZDDP}$ and $\mathbf{b}$ $\mathrm{BO}+\mathrm{ZDDP}+\mathrm{TDP}$ lubricant formulations
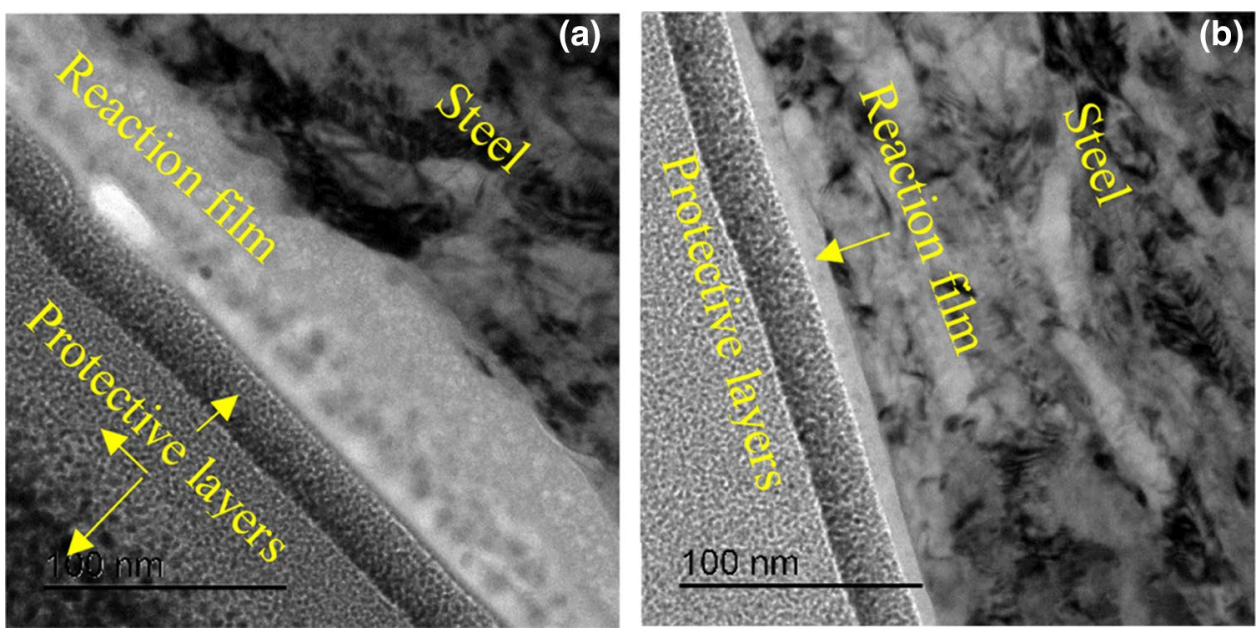

This shows OFMs' influence to attenuate micropit propagation which was further evidenced by SEM images shown in Fig. 6. In Fig. 6 it is evident that the addition of TDP to the lubricant leads to substantially lower micropitting density and smaller micropits on the surface. The lower micropitting density on the surface implied that the TDP-containing lubricant decayed micropit nucleation and smaller micropits can be attributed to hindered micropit propagation. These can be ascribed to the chemistry of the triboreaction film on the surface or simultaneous impact of wear and micropitting [25]. It has been shown that additives which form reaction films with superb wearprotection behaviour can accelerate micropitting through roughness evolution or hindering running-in processes $[1$, 25]. Therefore, a balanced performance through a modified reaction film deters premature micropitting evolution.

TEM images from FIB lamellas are presented in Fig. 7 showing tribofilms on the surface from an area close to a micropit and three layers of protective Pt coating. The ZDDP tribofilm showed a multilayer structure with embedded iron oxide wear particles in the film which agrees with papers by others in the literature $[13,26]$. A relatively more homogenous structure of the tribofilm from $\mathrm{BO}+\mathrm{ZDDP}+\mathrm{TDP}$ was manifested in the TEM images. The triboreaction film from ZDDP + TDP was considerably thinner compared to that from ZDDP alone.
ETA alleviated surface fatigue but impinged on wear performance of ZDDP. This was evident from ETA's rolling track profile (Fig. 5d) showing a significant depression. To identify the mechanism, XPS Fe $2 p$ and O 1s spectra were collected from roller surfaces and the spectra from $\mathrm{BO}+\mathrm{ZDDP}+$ ETA are shown in Fig. 8. In contrast to the other spectra from reaction films on the rollers lubricated with TA/TDP-containing oils, a significant peak was derived at $530.0 \pm 0.1 \mathrm{eV}$ from fitting $\mathrm{O} 1 \mathrm{~s}$ signal in the spectra from $\mathrm{BO}+\mathrm{ZDDP}+\mathrm{ETA}$. This peak can be assigned to metal oxides [8, 9]. In addition, a peak appeared at $706.8 \pm 0.1 \mathrm{eV}$ in $\mathrm{Fe} 2 \mathrm{p}$ spectrum from $\mathrm{BO}+\mathrm{ZDDP}+\mathrm{ETA}$ which was assigned to metallic $\mathrm{Fe}^{0}$ [9].

Iron oxide peaks which appear with an energy shift relative to $\mathrm{Fe}^{0}$ towards higher $\mathrm{BE}$ [9] were observed for all tribofilms from OFM-containing lubricants. However, the metallic iron was observed only in the tribofilm from $\mathrm{BO}+\mathrm{ZDDP}+\mathrm{ETA}$. Fe surfaces are passivated with a few nanometer of native oxides $\left(\mathrm{FeO}, \mathrm{Fe}_{2} \mathrm{O}_{3}\right)$ in atmospheric conditions and hence absence of the native layer implies a high degree of surface wear which exceeds the kinetics of surface repassivation. The rollers were stored with the residual oil on the surface until XPS analyses and rollers were introduced to the XPS chamber and subjected to the analyses immediately after the residual oil was washed 
Fig. 8 Detailed XPS spectra showing a Fe $2 \mathrm{p}$ and $\mathbf{b} \mathrm{O} 1 \mathrm{~s}$ signals in the tribofilm from $\mathrm{BO}+\mathrm{ZDDP}+\mathrm{ETA}$ on the MPR specimen

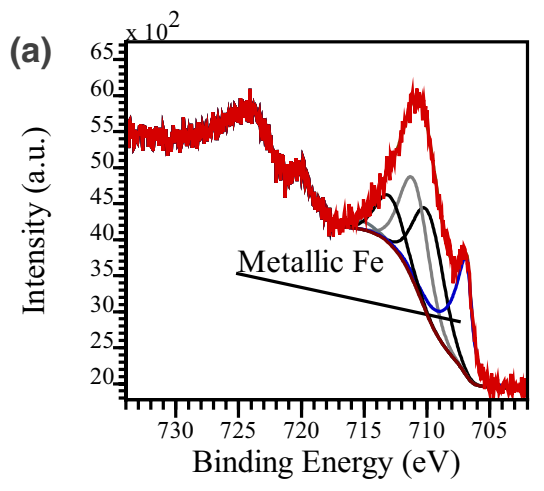

off the surfaces. Therefore, atmospheric oxidation was hindered and metallic iron can be detected.

Although friction reductions achieved by OFMs were not as pronounced as those observed in MTM friction tests, similar to the results in Fig. 2 ETA showed the most effective friction reduction followed by TDP and TA. ETA, TA and TDP decreased frictional forces by approximately $26 \%, 22 \%$ and $23 \%$, respectively.

\section{Discussion}

OFMs on steel surfaces are, in general, believed to reduce friction through surface adsorption which might lead to chemical reactions with steel surfaces depending on the chemistry of the polar moiety. The friction performance of an OFM on steel surfaces in the absence of other additives strongly depends on its packing density, the bonding energy of the polar head to the surface, and the length of hydrocarbon tail. It has been shown that double bonds, especially cis bonds in the hydrocarbon tail, deteriorate packing density resulting in less intra molecular van der Waals interactions between neighbouring tails and hence disrupt friction reduction performance of OFMs [27]. The hydrocarbon chain in the current study was a tallow chain which has a high cis to trans bond ratio and a high degree of unsaturation (see Table 3) especially in C16 and C18 chains. Therefore, kinks in tallow result in a poor packing density. The low packing density of the OFMs used in this study provides free surfaces for the ZDDP film to form and grow.

The OFMs consisted of the same hydrocarbon tail and therefore different film formation kinetics, friction, and surface fatigue performances originated from disparate chemistries of polar heads. Adsorption of amine-based OFM molecules on iron oxide surfaces has been shown in previous studies $[14,28]$ and can be suggested from Stribeck curves at the start of the test shown in Fig. 2a. The Stribeck curves exhibited significantly lower friction coefficients in lubricants with an OFM compared to friction in $\mathrm{BO}+\mathrm{ZDDP}$. Iron oxide on steel surfaces catalyses ZDDP film formation [29] and hence the surface blocked by OFM molecules is not available for ZDDP-film formation, delaying ZDDPtribofilm formation. Therefore, the competition between the OFM molecules and ZDDP molecules to form a film governs the kinetics of overall tribofilm formation. In addition, the metal surface may be exposed to ZDDP (or ZDDP's decomposition products) through the removal of OFMs from the surface in the presence of shear stresses and wear at the tribological contact, leading to ZDDP-tribofilm formation. Eriksson [30] studied adsorption behaviour of an OleylAmine (OA) and a Ethoxylated OleylAmine (EOA) using a Quartz Crystal Microbalance (QCM) and showed a greater adsorption and higher surface coverage of EOA over OA, implying superior adsorption of ETA compared to TA and TDP. Furthermore, two hydroxyl groups in ETA prompt relatively strong nucleophilic properties and consequently ETA coordinates to the surface's positive sites (e.g. iron cations). Therefore, the slower kinetics of film formation from ZDDP + ETA can be attributed to the greater propensity of ETA to steel surfaces. The larger polar head of ETA in comparison to TA and TDP which occupies a larger surface area might also be a contributing factor.

Amine-based OFMs can also chemically interact with ZDDP molecules in the bulk lubricant which influences film formation kinetics and tribological performance. $\mathrm{N}$ can act as a ligand through its lone pair of electrons in hybridized $s p^{3}$ orbitals. Shiomi et al. [11] showed that (di)amines as ligands can form metal complexes with the $\mathrm{Zn}$ atom in ZDDP. The metal complexes generated are larger molecules which result in larger steric hindrance and inferior adsorption on the surface, and also lead to a reduction in the concentration of free ZDDP molecules to from ZDDP-film. Therefore, metal complex formation in the bulk lubricant may induce a further delay in tribofilm formation. Conversely, the hydroxyethyl group $\left(\left(\mathrm{CH}_{2}\right)_{2} \mathrm{OH}\right)$ in ETA exerts steric hindrance around $\mathrm{N}$ which might decay complex formation between $\mathrm{Zn}$ and 
$\mathrm{N}$ resulting in more free ETA to adsorb on the surface and hence less surface for ZDDP to form a film.

TA showed a stronger delaying effect compared to TDP. Siegel et al. [31] showed that diamine has a greater dipole moment $\left(\mu_{\mathrm{b}}\right)$ compared to amine while $\mu_{\mathrm{b}}$ in diamine is not twice the $\mu_{\mathrm{b}}$ in amine. This means that TA has more adsorption potential compared to TDP, if TDP is not protonated and is adsorbed through terminal N. Protonation of TDP and TA disturbs electron density pattern around the polar head. This might hinder the accessibility of electron pair in $\mathrm{N}$ resulting in altered surface adsorption. In addition, TA has a smaller molecular structure, indicating that TA adsorbs more easily on the steel surface due to the less steric hindrance and hence can induce greater delaying effect when compared to TDP. Therefore, among the OFMs examined in this study, the greater delaying effect on ZDDP-film formation results from superior extent of the OFM adsorption onto the surface which increases along the series of OFMs TDP $<$ TA $<$ ETA. The friction performance of an OFM in an oil with no other additive depends on its surface adsorption characteristics including chemistry of the polar head and packing density [32]. Accordingly, in MTM SS and MPR tests, where thin films in the order of 5-20 nm (Fig. 7) were formed on surfaces, the friction performance of OFMs most probably depends on the extent of OFM adsorption onto the surface. Therefore, an enhanced friction reduction was observed with the OFM showing greater adsorption characteristics; when considering that the hydrocarbon tail was the same for all the OFMs.

The impact of OFMs on tribofilm thickness and formation rate can be addressed through shear-assisted ZDDPtribofilm formation $[33,34]$ as a potential alternative mechanism. Since the change in the lubricant viscosity as a result of OFM addition was insignificant and so too the change in Hertzian contact area, the friction coefficient is proportional to the contact shear stresses. Adsorption of OFMs onto steel surfaces reduced shear stresses within the contact. This indicates that for ZDDP to form a film, higher energy inputs are required to overcome its activation energy barrier. Therefore, a thinner tribofilm, formed at a slower rate, is expected for the OFM that reduced the friction coefficient to a greater extent, as demonstrated in MTM SS test results. In our previous paper [2], we showed that addition of TDP to ZDDP blends generated smoother tribofilms (suggested in Fig. 3) leading to enhanced lubricant entrainment into the contact and hence reduced frictional forces [2, 35]. Pad features in ZDDP-tribofilms are believed to from at asperity conjunctions which promote the film-growth (since they are subjected to higher shear stresses) [33]. Therefore, smoother tribofilms from OFM + ZDDP blends hindered the growth of tribofilms and hence thinner tribofilms were formed (Figs. 1, 7).
The addition of OFMs reduced the boundary friction in the first Stribeck curve at the start of the tests, suggesting OFM adsorption onto the surface. Also, the OFMs reduced the friction-enhancing behaviour of the ZDDP-film. An earlier shift of mixed/boundary regime to fluid film lubrication in Stribeck curves was achieved with OFMs. The less effective friction reduction by OFMs in MPR tests in comparison to MTM SS tests may be attributed to higher distortion in the OFM film structure [36] due to the higher combinedroughness and/or the surface fatigue features on the surfaces of MPR rollers. Simulation work suggested that nanoscale roughness can result in a disordered monolayer [36] which affected friction performance. Ewen et al. [37] suggested that friction reduction by OFMs was achieved through easy slip planes formed between solid-like OFM monolayers and lubricant films at high surface coverages. They postulated liquid-like monolayers at low surface coverages with inferior friction reduction properties. A simulation work by Doig et al. [28] suggested that, at a lower surface coverage, amines lay more flat towards the surface and greater lubricant penetration into the monolayer developed a layered structure. Therefore, micropits and the higher surface roughness on the surface of MPR rollers compared to MTM SS specimens disrupted OFM adsorption resulting in a higher friction coefficient. In contrast, the surfaces on MTM SR samples were fully covered with relatively thick tribofilms. The detected $\mathrm{N}$ and $\mathrm{P}$ signals in XPS results (Fig. 4 and Table 4) suggest chemical interactions of amine with the ZDDP film. This showed that OFMs used in this study not only adsorbed onto the steel surface but also interacted with phosphates in ZDDP-film. Miklozic et al. [12] examined a variety of OFMs with different polar heads in combination with ZDDP and suggested that an effective OFM should also deliver friction reduction on the surface of anti-wear tribofilms.

Tribo-contacts in BO +ZDDP-lubricated systems induce zinc (poly)phosphates on steel surfaces and $\mathrm{Zn}$ to $\mathrm{P}$ ratio in the zinc (poly)phosphates has been used in evaluating the phosphate chain length [10, 29]. The Zn 3s-P 2 $\mathrm{p}_{3 / 2} \Delta \mathrm{BE}$ values for tribofilms in this study suggested a similar phosphate chain length but greater $\mathrm{Zn} / \mathrm{P}$ and $\mathrm{S} / \mathrm{P}$ ratios and $\alpha^{\prime}$ values for tribofilms from OFMs (Table 4) suggested changes in $\mathrm{Zn}$ state in the tribofilm probably implying enhanced $\mathrm{ZnS}$ formation $[23,24]$. These imply that $\mathrm{Zn}^{2+}$ cations were partly exchanged with protonated organic compounds. According to Brønsted-Lowry theory, amines can bind to a proton $\left(\mathrm{H}^{+}\right)$ to form a weak $\mathrm{R}^{-\mathrm{NH}^{3+}}$ acid. The protonation of amines were confirmed in our XPS data. Following protonation, $\mathrm{R}-\mathrm{NH}^{3+}$ might react with phosphate ions (hard base) according to Hard and Soft Acids and Bases (HSAB) concept and from amine/ammonium phosphates. Therefore, the OFMs used in this study adsorbed onto the ZDDP-tribofilm and chemically interacted with the phosphate chains which influenced wear and friction performance. 
As shown in Figs. 3 and 5, OFMs improved the wear performance to a certain extent compared to $\mathrm{BO}+\mathrm{ZDDP}$ under test conditions defined in this study. Our experiments using MPR with TDP blended in BO (not shown here) and post-test XPS analysis evidenced wear protection characteristics of TDP and N interaction with the surface. Our results are in agreement with Eriksson [30] observations, showing anti-wear properties of OA and EOA with and without ZDDP. Eriksson [30] reported that OFM enhances anti-wear performance when added to ZDDP up to concentration ratios of amine/ZDDP $\leq 1$ under sliding conditions. The wear protection characteristics of TDP indicate a stable adsorption on the steel surface with a contribution of chemical interactions with the surface. The chemical interaction of an amine with $\mathrm{Fe}$ surfaces has been reported by Wood et al. [14], who studied the adsorption of hexadecylamine from a model oil (hexadecane) onto an iron oxide surface. They found a dense tilted hexadecylamine monolayer with a thickness of 16-20 Å formed through lone pair electron donation from $\mathrm{N}$ in amine to iron cations. They also suggested interdigitation of oil molecules with the monolayer, which probably impacts friction and wear performances through providing the contact with a retained oil layer. The retained oil between the contacting bodies enhances oil entrainment into the contact resulting in less asperity-asperity contacts. At lower surface coverages the interdigition of the lubricant with the monolayer has been suggested to become pronounced [28]. Therefore, with kinks in the OFMs used in this study, a greater lubricant penetration into the monolayer might reduce the chance of lubricant starvation and hence surfaces were separated more effectively. Ewen et al. [36] modelled OFM monolayers and showed that adsorbed OFM molecules on the surface asperities can prevent asperity-asperity contacts under pressures of the order of GPa. Therefore, OFM adsorption can alleviate solid-solid contacts under certain conditions. Asperity-asperity contacts between surfaces induce micropitting and hence monolayers formed from OFMs in this study alleviated micropitting nucleation on the surface (Fig. 5). In industrial applications, fully-formulated gear lubricants, which comprise the same amine-based OFMs used in this study, have been shown to prevent pitting and spalling of gear teeth [38].

The XPS results (Table 4) evidenced a reduction in the contribution of $\mathrm{C}-\mathrm{O}$ and $\mathrm{O}-\mathrm{C}=\mathrm{O}$ bonds when either TDP or TA was present in the lubricant implying anti-oxidant activity of the amine-based additives [39]. It has been shown that alkylated diphenylamine molecules reduce wear and friction coefficient of sliding steel-steel surfaces [39]. The friction coefficient and wear reduction was attributed to the free radical scavenging behaviour and/or suppression of the catalytic activity of metallic surfaces. The tribofilms formed through interactions between the lone pair electron of $\mathrm{N}$ and/ or $\pi$ electrons in the aromatic ring and iron surfaces were proposed to mask the catalytic activity of the worn steel surfaces [39]. Therefore, anti-oxidant behaviour and organic films generated from TDP/TA and through its interaction with ZDDP can contribute to factors causing wear and friction coefficient reductions observed in this study.

Figure 5, however, showed a substantial rise in wear as a result of ETA addition to BO + ZDDP. This contradicts the previous results showing the impact of EOA on wear reduction in combination with ZDDP under sliding conditions [30]. This can be attributed to the high affinity of ETA to the surface which almost hindered ZDDP film formation on the MPR roller surface. The higher surface adsorption of an ethoxylated amine in comparison to the non-ethoxylated amine has been reported in the literature [30]. Our XPS results showed that $\mathrm{P}$ concentration and $\mathrm{Zn} / \mathrm{P}$ atomic concentration ratio in tribofilms reduced from around 11 at $\%$ and 1.1 in TA + ZDDP to 4.5 at $\%$ and 0.3 in ETA + ZDDP respectively. In addition, a contribution of metallic iron and a significant oxide peak were observed in the tribofilm from ETA + ZDDP-(Fig. 8) indicating extensive wear of the surface. The XPS results confirmed that ETA mitigated phosphate formation in micropitting tests resulting in excessive wear. Costa et al. [40] showed that addition of ethanol to a lubricant delayed ZDDP-tribofilm formation and eventually led to a thinner film on the surface. In addition, hydrated ethanol removed a preformed ZDDP-tribofilm which was attributed to localised chemical-etching action of hydrated ethanol [40]. The functional group in ethanol is hydroxyl group and ETA with two hydroxyl groups is expected to induce similar effects. Therefore, ETA blocked the surface hindering ZDDP-tribofilm formation and digested formed phosphates on the surface leading to substantial wear of the roller surfaces. The surface adsorption of ethoxylated amine molecules has been suggested to form a close to a monolayer structure [30]. However, under shear forces, a proportion of ETA molecules can form surface reverse-micelles as a result of relatively higher polarity of ETA in the non-polar base oil (PAO) used in this study [41]. The micelles are bulkier and can block larger areas on the surface bringing about deteriorated wear performance.

In spite of reduced micropitting through addition of the OFMs, abrasive marks were more pronounced on surfaces from lubricants with the OFMs suggesting intensified abrasive wear (Fig. 5). Abrasive wear is induced by hard metallic oxides (i.e. iron oxide) in tribological steel-steel contacts. The observation of enhanced abrasive wear can be addressed considering HSAB reactions. Long chain zinc phosphates are hard bases and according to HSAB react with iron cations $\left(\mathrm{Fe}^{3+}\right)$ to eliminate iron oxide wear particles and hence mitigate abrasive wear [29]. OFMs tampered with ZDDP film formation and induced thinner phosphate films (Fig. 1), and therefore, they favour abrasive wear which can cause catastrophic damages in some applications. 


\section{Conclusion}

Findings in this study showed that three types of aminebased OFMs chemically interact with steel surfaces and, more importantly, with ZDDP tribo-film under rolling-sliding conditions. The chemical interactions result in friction reduction and improved wear performance (except ETA in severe surface fatigue experiments). The friction-enhancing behaviour of ZDDP tribofilm was alleviated to a certain degree through the addition of the OFMs. Friction reduction depends on the extent of OFM adsorption which can be correlated to the extent that the OFM delays ZDDP-film formation. All examined OFMs mitigated the ZDDP effect on micropitting under test conditions defined in this study. However, wear performance depends both on OFM adsorption and its interaction with ZDDP-film. High affinity of ETA to the surface-hindered ZDDP film hence resulted in intensified wear. Therefore, findings in this study suggest that a careful selection of OFMs with a tailored concentration is essential to realise benefits of micropitting reduction and wear protection simultaneously. In addition, the selection of OFM depends on the application and the nature of the damage (wear, friction or fatigue) in the application.

Acknowledgements This study was funded by the FP7 program through the Marie Curie Initial Training Network (MC-ITN) entitled "FUTURE-BET-Formulating an Understanding of Tribocorrosion in ArdUous Real Environments - Bearing Emerging Technologies" (317334) and was carried out at University of Leeds and SKF Engineering and Research Centre. The authors would like to thank to all FUTURE-BET partners whom had kind discussions on the topic and the methodology. The OFM additives are provided by Dr. Joke Speelman from Nouryon (formerly AkzoNobel) and is gratefully acknowledged. The authors express their gratitude to SKF for the kind permission to publish this work.

\section{Compliance with Ethical Standards}

Conflicts of interest There are no conflicts of interest to declare.

Open Access This article is distributed under the terms of the Creative Commons Attribution 4.0 International License (http://creativeco mmons.org/licenses/by/4.0/), which permits unrestricted use, distribution, and reproduction in any medium, provided you give appropriate credit to the original author(s) and the source, provide a link to the Creative Commons license, and indicate if changes were made.

\section{References}

1. Laine, E., Olver, A., Beveridge, T.: Effect of lubricants on micropitting and wear. Tribol. Int. 41, 1049-1055 (2008)

2. Soltanahmadi, S., Morina, A., van Eijk, M.C., Nedelcu, I., Neville, A.: Investigation of the effect of a diamine-based friction modifier on micropitting and the properties of tribofilms in rolling-sliding contacts. J. Phys. D 49, 505302 (2016)
3. de la Guerra Ochoa, E., Otero, J.E., Tanarro, E.C., Munoz-Guijosa, J., del Rio Lopez, B., Cordero, C.A.: Analysis of the effect of different types of additives added to a low viscosity polyalphaolefin base on micropitting. Wear 322:238-250 (2015)

4. Ratoi, M., Niste, V.B., Alghawel, H., Suen, Y.F., Nelson, K.: The impact of organic friction modifiers on engine oil tribofilms. RSC Adv. 4, 4278-4285 (2014)

5. Farn, R.J.: Chemistry and Technology of Surfactants. Wiley, New York (2008)

6. Boyer, Ivan J., Bart Heldreth, C.L.B.: Safety assessment of pegs cocamine and related ingredients as used in cosmetics. Cosmetic Ingredient Review, Place (2015)

7. Soltanahmadi, S., Morina, A., van Eijk, M.C.P., Nedelcu, I., Neville, A.: Tribochemical study of micropitting in tribocorrosive lubricated contacts: the influence of water and relative humidity. Tribol. Int. 107, 184-198 (2017)

8. Nedelcu, I., Piras, E., Rossi, A., Pasaribu, H.: XPS analysis on the influence of water on the evolution of zinc dialkyldithiophosphate-derived reaction layer in lubricated rolling contacts. Surf. Interface Anal. 44, 1219-1224 (2012)

9. Moulder, J.F.: Handbook of X-ray photoelectron spectroscopy. Phys. Electron. 5, 230-232 (1995)

10. Crobu, M., Rossi, A., Mangolini, F., Spencer, N.D.: Chain-lengthidentification strategy in zinc polyphosphate glasses by means of XPS and ToF-SIMS. Anal. Bioanal. Chem. 403, 1415-1432 (2012)

11. Shiomi, M., Tokashiki, M., Tomizawa, H., Kuribayashi, T.: Interaction between zinc dialkyldithiophosphate and amine. Lubr. Sci. 1, 131-147 (1989)

12. Miklozic, K.T., Forbus, T.R., Spikes, H.A.: Performance of friction modifiers on ZDDP-generated surfaces. Tribol. Trans. 50, 328-335 (2007)

13. Martin, J., Grossiord, C., Le Mogne, T., Igarashi, J.: Role of nitrogen in tribochemical interaction between Zndtp and succinimide in boundary lubrication. Tribol. Int. 33, 453-459 (2000)

14. Wood, M.H., Welbourn, R.J., Charlton, T., Zarbakhsh, A., Casford, M., Clarke, S.M.: Hexadecylamine Adsorption at the iron oxide-oil interface. Langmuir 29, 13735-13742 (2013)

15. Hersh, L., Onyiriuka, E., Hertl, W.: Amine-reactive surface chemistry of zinc phosphate glasses. J. Mater. Res. 10, 2120-2127 (1995)

16. Matsumoto, K. Surface chemical and tribological investigations of phosphorus-containing lubricant additives [Doctor of Philosophy]: Technische Wissenschaften ETH Zürich; (2003)

17. Möhrle, H., Kampe, C., Herbke, J., Nowak, H.-J., Wendisch, D., Storp, S.: Doppelsalzbildung bei Amiden und vinylogen Amiden. Monatshefte für Chemie/Chemical Monthly 109, 1295-1303 (1978)

18. Greenberg, A., Breneman, C.M., Liebman, J.F.: The Amide Linkage: Structural Significance in Chemistry, Biochemistry, and Materials Science. Wiley, New York (2002)

19. Yamaguchi, E., Zhang, Z., Kasrai, M., Bancroft, G.: Study of the interaction of ZDDP and dispersants using X-ray absorption near edge structure spectroscopy - part 2: tribochemical reactions. Tribol. Lett. 15, 385-394 (2003)

20. Zhang, Z., Kasrai, M., Bancroft, G., Yamaguchi, E.: Study of the interaction of ZDDP and dispersants using X-ray absorption near edge structure spectroscopy—part 1: thermal chemical reactions. Tribol. Lett. 15, 377-384 (2003)

21. Zhang, Z., Yamaguchi, E., Kasrai, M., Bancroft, G.: Interaction of ZDDP with borated dispersant using XANES and XPS. Tribol. Trans. 47, 527-536 (2004)

22. Komvopoulos, K., Do, V., Yamaguchi, E., Yeh, S., Ryason, P.: $\mathrm{X}$-ray photoelectron spectroscopy analysis of antiwear tribofilms produced on boundary-lubricated steel surfaces from sulfur-and phosphorus-containing additives and metal deactivator additive. Tribol. Trans. 47, 321-327 (2004) 
23. Brion, D.: Etude par spectroscopie de photoelectrons de la degradation superficielle de FeS 2, CuFeS 2, ZnS et PbS a l'air et dans l'eau. Appli. Surf. Sci. 5, 133-152 (1980)

24. Deroubaix, G., Marcus, P.: X-ray photoelectron spectroscopy analysis of copper and zinc oxides and sulphides. Surf. Interface Anal. 18, 39-46 (1992)

25. Morales-Espejel, G.E., Rycerz, P., Kadiric, A.: Prediction of micropitting damage in gear teeth contacts considering the concurrent effects of surface fatigue and mild wear. Wear 398-399, 99-115 (2018)

26. Martin, J.M., Onodera, T., Minfray, C., Dassenoy, F., Miyamoto, A.: The origin of anti-wear chemistry of ZDDP. Faraday Discuss. 156, 311-323 (2012)

27. Beltzer, M.: Assessing adsorption of conventional friction modifying molecules by relative contact potential difference measurements. J. Tribol. 114, 675-682 (1992)

28. Doig, M., Camp, P.J.: The structures of hexadecylamine films adsorbed on iron-oxide surfaces in dodecane and hexadecane. Phys. Chem. Chem. Phys. 17, 5248-5255 (2015)

29. Martin, J.M.: Antiwear mechanisms of zinc dithiophosphate: a chemical hardness approach. Tribol. Lett. 6, 1-8 (1999)

30. Eriksson, K.: Fatty Amines as Friction Modifiers in Engine OilsCorrelating Adsorbed Amount to Friction and Wear Performance [Master]. Chalmers University of Technology, Gothenburg (2014)

31. Siegel, G.G., Herrera, F., Cappelle, P., Huyskens, P.L.: Dipolar study of primary aliphatic amines and diamines. J. Mol. Struct. 159, 355-363 (1987)

32. Spikes, H.: Friction modifier additives. Tribol. Lett. 60, 1-26 (2015)

33. Zhang, J., Spikes, H.J.T.L.: On the mechanism of ZDDP antiwear film formation. Tribol. Lett. 63, 24 (2016)
34. Spikes, H.J.F.: Stress-augmented thermal activation: Tribology feels the force. 6, 1-31 (2018)

35. Dawczyk, J., Morgan, N., Russo, J., Spikes, H.J.T.L.: Film thickness and friction of ZDDP. Tribofilms 67, 34 (2019)

36. Ewen, J.P., Echeverri Restrepo, S., Morgan, N., Dini, D.: Nonequilibrium molecular dynamics simulations of stearic acid adsorbed on iron surfaces with nanoscale roughness. Tribol. Int. 107, 264-273 (2017)

37. Ewen, J.P., Gattinoni, C., Morgan, N., Spikes, H.A., Dini, D.: Nonequilibrium molecular dynamics simulations of organic friction modifiers adsorbed on iron oxide surfaces. Langmuir 32, 4450-4463 (2016)

38. Mark, T., Devlin, H.T.R.: Lubricant compositions. In: Patent US (ed.). Afton Chemical Corporation, Richmond, WA (US) Place Afton Chemical Corporation, Richmond (2008)

39. Singh, A., Gandra, R.T., Schneider, E.W., Biswas, S.K.: Studies on the aging characteristics of base oil with amine based antioxidant in steel-on-steel lubricated sliding. J. Phys. Chem. C 117, 1735-1747 (2013)

40. Costa, H.L., Spikes, H.A.: Impact of ethanol on the formation of antiwear tribofilms from engine lubricants. Tribol. Int. 93, 364-376 (2016)

41. Bradley-Shaw, J.L., Camp, P.J., Dowding, P.J., Lewtas, K.: Glycerol monooleate reverse micelles in nonpolar solvents: computer simulations and small-angle neutron scattering. J. Phys. Chem. B 119, 4321-4331 (2015)

Publisher's Note Springer Nature remains neutral with regard to jurisdictional claims in published maps and institutional affiliations. 